\title{
Tribological and Rheological Characterization of New Completely Biogenic Lubricating Greases: A Comparative Experimental Investigation
}

\author{
Nazli Acar ${ }^{1, *}$, Erik Kuhn ${ }^{1}$ and José M. Franco ${ }^{2}$ (D) \\ 1 Laboratory of Machine Elements and Tribology, Department of Mechanical Engineering and Production, \\ Faculty of Engineering Technology and Computer Science, Hamburg University of Applied \\ Sciences (HAW-Hamburg), Berliner Tor 21, 20099 Hamburg, Germany; erik.kuhn@haw-hamburg.de \\ 2 Pro2TecS-Chemical Product and Process Technology Research Centre, Complex Fluid \\ Engineering Laboratory, Department of Chemical Engineering, University of Huelva, 21071 Huelva, Spain; \\ franco@uhu.es \\ * Correspondence: nazli.acar@haw-hamburg.de; Tel.: +49-4042-8758-744
}

Received: 22 March 2018; Accepted: 2 May 2018; Published: 5 May 2018

\begin{abstract}
Against the background of raw material shortage and the ever-expanding environmental consciousness, the use of biodegradable greases becomes more and more important. The aim of this experimental work is to investigate the tribological response of completely biodegradable greases. Complete biodegradable lubricating greases were formulated with high-oleic sunflower oil (HOSO) and/or castor oil, and different biodegradable thickener agents such as natural cellulose fibers of different lengths and some derivatives, as well as glyceryl and sorbitan stearates. To investigate the friction process, the model greases were tribologically examined with a nanotribometer at a normal force of $200 \mathrm{mN}$ using a material combination of a steel ball on a steel disc. All frictional results, along with the volumes of wear tracks and micrographs of the main contacting area on the steel plate, are presented and discussed. In addition to this, rotational transient flow measurements were carried out on a rheometer at different temperatures to monitor the evolution of the shear stress with time at a constant shear rate, and to characterize the internal friction behavior by quantifying the energy density. All results were also analyzed from an energetic point of view.
\end{abstract}

Keywords: biogenic lubricating greases; tribology; rheology; friction; transient flow

\section{Introduction}

Lubricating greases have a wide range of applications and a long history. A consequence of intensive research and development in the past is the number of the so-called bio-grease formulations reported in the literature or even industrially produced. These lubricants consist of a vegetable-derived oil like castor oil or sunflower oil and traditional thickeners like metal soaps [1-6].

More recently, a further development from biodegradable lubricants to completely biogenic or bio-sourced lubricants has been initiated. It means that both the base oil and the thickener consist of biogenic material. First research works on completely biogenic lubricating greases were done by Sánchez, Franco, and co-workers [7-13], where castor oil or soybean oil was used as biodegradable lubrication oil and traditional thickener agents were replaced by natural thickeners like cellulose derivatives, chitin, chitosan, glyceryl stearates or sorbitan stearates. These comparative studies of bio-based greases with other traditional greases like lithium-12-hydroxysteate lubricating grease show that some of the bio-based greases provided comparable thermal, mechanical, and rheological properties for potential lubricating applications. Moreover, in one study [9], the evolution of the friction coefficient in several tribological tests performed using several ball-on-disc configurations and 
coupling materials was investigated for the different biodegradable lubricating greases. The model greases, containing sorbitan monostearate, glyceryl monostearate, or acylated chitosan as thickener agents and castor oil as base oil, generally provided lower values of the friction coefficient than some traditional lithium greases in all tribological tests.

The main aim of the application of a lubricant is the prevention of the direct contact of the two solid rubbing bodies. That means for a friction balance that the friction behavior (the so-called fluid friction) of the lubricant plays an important role for the friction of a whole tribo-system. In addition, the loss of material as one type of wear will be reduced. In most practical situations, grease-lubricated contacts work in a state of mixed friction. This means the friction energy consists of a part of fluid friction and a part of solid friction. Mixed-friction was also observed for the tribometer tests reported in this paper. Using a ball-on-plate configuration with a grease-lubricated steel-steel contact that measured friction force, the friction coefficient can represent the mixed friction under these conditions. In addition, rheometer tests were performed to investigate the fluid friction inside the grease film as the second part of mixed friction. The energy density concept was used to quantify the energy expenditure for a shearing process. In this paper, grease samples containing newly developed biogenic thickeners and HOSO and/or castor oil as base oils were investigated. The aim of the paper is to present comparative results on the frictional response of a number of new completely biogenic model greases.

\section{Experimental Section}

\subsection{Materials}

A series of completely biogenic lubricating greases was produced by Fuchs Europe Schmierstoffe (Mannheim, Germany) and Fuchs Lubritech (Kaiserslautern, Germany). To compare the tribological behavior of the greases, two reference grease samples (R1 and R2) were added for the investigation. The compositions of the grease samples are listed in Table 1.

Table 1. Compositions of greases provided by Fuchs.

\begin{tabular}{ccc}
\hline Grease Sample (Code) & Base Oil & Substance of Content \\
\hline R1 & Synthetic Ester & Lithium/Calcium Soap \\
R2 & HOSO & Lithium-12-hydroxystearate \\
1 & HOSO and Castor oil & Beeswax, glyceryl monostearate and cetyl alcohol \\
2 & HOSO and Castor oil & Glyceryl monostearate, cetyl alcohol and sorbitan monostearate \\
3 & HOSO & Cellulose ether and glycerin \\
4 & HOSO & Isoprene derivative \\
5 & HOSO & Lignosulfonate \\
6 & HOSO & Natural cellulose fibers $18 \mu \mathrm{m}$ \\
7 & HOSO & Corncob grits $80-120 \mu \mathrm{m}$ \\
8 & HOSO & Natural cellulose $20-40 \mu \mathrm{m}$ \\
9 & HOSO & Natural wood pulp from softwood $70-150 \mu \mathrm{m}$ \\
\hline
\end{tabular}

${ }^{1}$ HOSO: high-oleic sunflower oil.

To extend the experimental work, four completely biogenic grease samples from Pro2TecS (University of Huelva, Huelva, Spain) were used and investigated. These four samples are listed in Table 2.

Table 2. Compositions of greases provided by Pro2TecS.

\begin{tabular}{|c|c|c|}
\hline Grease Sample (Code) & Oil & Thickener \\
\hline S1 & Castor Oil & Lignin/PEGDGE ${ }^{1}$ (weight ratio of $1 / 0.25$ ) \\
\hline S2 & Castor Oil & Lignin/PEGDGE (weight ratio of $1 / 1$ ) \\
\hline S3 & Castor Oil & Lignin/HMDI ${ }^{2}$ (weight ratio of $1 / 2$ ) \\
\hline S4 & Castor Oil & Lignin/HMDI (weight ratio of 1/1) \\
\hline
\end{tabular}


The base oil for all Fuchs samples is high-oleic sunflower oil (HOSO) or a combination of HOSO and castor oil. Many efforts were made to create effective and efficient biogenic thickeners by testing different natural products, for example, beeswax, natural cellulose, glyceryl- and sorbitan monostearate, in different combinations and proportions. Unfortunately, here we are not able to present the percentage of each thickener.

The second group of grease samples used castor oil as the base oil and lignin as the thickener agent, once chemically modified with an epoxy compound (polyethylene glycol diglycidyl ether (PEGDGE)) or hexamethylene diisocyanate (HMDI) to promote the chemical interaction with the base oil $[14,15]$.

\subsection{Tribological Tests}

A nanotribometer from CSM Instruments (Peseux, Switzerland) is used to determine the friction values of tribologically stressed material combinations. The test set-up consists of a static ball, which is fixed to a cantilever to avoid rolling, and a rotating disc. In the nanotribometer, the disc is stressed by pressure caused by applying a normal force. The ball-on-disc apparatus works in rotational mode. The fiber-optic sensors measure the deflection of the cantilever in radial (frictional force) and normal (normal force) directions, and by the precise calibration of the spring constant of the cantilever in both directions determined into frictional and normal forces.

In the Laboratory for Machine Elements and Tribology (MuT) of HAW-Hamburg, all tests were performed using material combinations of a steel ball (100Cr6) with $1 \mathrm{~mm}$ diameter on a steel disc (115CrV3, hardness 60-62 HRC, Zentrale Laborwerkstatt at the HAW-Hamburg, Hamburg, Germany) in rotational mode. All the steel discs were metallographically grinded and polished with a soft finish diamond paste of particle size $3 \mu \mathrm{m}$ in the last polishing step. Normal load was kept constant at $200 \mathrm{mN}$ with resulting Hertzian stress values of $1.2 \mathrm{GPa}$, and relative speed was varied with values of $40 \mathrm{~mm} \cdot \mathrm{s}^{-1}$ and $60 \mathrm{~mm} \cdot \mathrm{s}^{-1}$. Under these conditions, a mixed-friction lubricated contact was achieved. The evolution of the friction coefficient with time was followed during $34 \mathrm{~min}$ (with relative speed $40 \mathrm{~mm} \cdot \mathrm{s}^{-1}$ ) and $22 \mathrm{~min}$ (with relative speed $60 \mathrm{~mm} \cdot \mathrm{s}^{-1}$ ). Each test was performed with each of the model grease samples and repeated three times at an ambient temperature of $22 \pm 1^{\circ} \mathrm{C}$ to calculate a quite accurate average friction coefficient. The friction and wear behaviors of the model greases were investigated under these conditions because they are optimal/ideal parameters of the nanotribometer.

The wear marks, which were produced from the three-time repetition of measurement in the same track at the nanotribometer, were analyzed by means of white light Interferometry (by Zygo Nexview, Middlefield, $\mathrm{OH}, \mathrm{USA})$. In this investigation, biogenic grease samples were examined to quantify the wear in the solids.

\subsection{Rheological (Rotational Transient Flow) Tests}

As previously described, a grease-lubricated contact works in a number of applications in the mixed-friction regime. It means that two subprocesses of the friction energy influence the whole system. Those are solid friction (e.g., deformation of asperities) and fluid friction (that arises inside the grease film).

To get an impression of the internal fluid friction behavior, rheometer tests were performed on the different grease samples studied. Figure 1 shows an example of the typical curve for a rotational transient test at a constant shear rate $(\dot{\gamma}=$ const. $)$.

A previously reported model [16] was used to characterize the described friction behavior in a rotational transient test from an energy point of view. It defines a rheological energy density, $\left(e_{\text {rheo }}\right)$, which represents energy expenditure per stressed grease volume. The rheological energy density can be calculated by the integration of the second part of the $\tau$ vs. $t$ curve at a constant shear rate $(\dot{\gamma})$ as follows [17]:

$$
\mathrm{e}_{\text {rheo }}=\dot{\gamma} \cdot \int_{\mathrm{t}_{\max }}^{\mathrm{t}} \tau(\mathrm{t}) \mathrm{dt}
$$


where $t_{\max }$ is the time necessary to reach the maximum shear stress $\left(\tau_{\max }\right)$ and $t$ is the shearing time. Moreover, the following empirical model was introduced for the shear stress as a function of time [18]:

$$
\tau(t)=\tau_{\lim } \cdot\left(\frac{t}{t_{\lim }}\right)^{-n}
$$

where $t_{\text {lim }}$ is the time necessary to reach the steady-state shear stress $\left(\tau_{\lim }\right)$, and $n$ is the dimensionless exponent which describes the intensity of the structure degradation and can be determined with the help of a potential regression. An important explanation here is that $\tau_{\lim }$ and $t_{\lim }$ represent the stationary state of the grease. Using Equations (1) and (2), the energy expenditure per stressed volume can be estimated for a defined stress period.

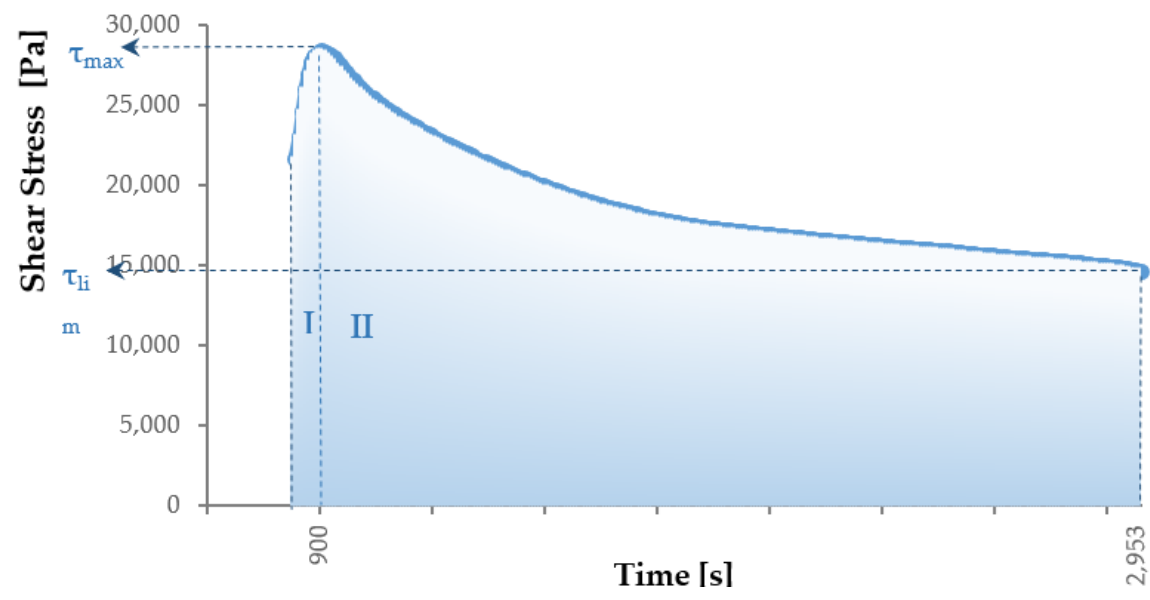

Figure 1. Example of a stress vs. time curve obtained in rotational transient flow tests.

The energetic interpretation of the two distinct regions of the shear stress versus time curve can play an important role in providing some information about the rheological and tribological behavior of the lubricating greases in the flow process. In this work, the energetic study was focused on the second part of the $\tau(t)$ curve - that is, after reaching the maximum stress value-evaluated at different temperatures.

The rotational transient flow measurements of complete biogenic greases were carried out on a MCR-302 rheometer (Anton Paar GmbH, Graz, Austria) in the Laboratory for Machine Elements and Tribology (MuT) of HAW-Hamburg. In this study, the model and reference greases were tested using a plate-plate system with a gap of $1 \mathrm{~mm}$ due to their coarse structure. All tests were performed by applying a constant shear rate of $1 \mathrm{~s}^{-1}$ at different temperatures $\left(25^{\circ} \mathrm{C}, 40^{\circ} \mathrm{C}\right.$ and $\left.80{ }^{\circ} \mathrm{C}\right)$. The measuring time was set at $3600 \mathrm{~s}$ and the selected greases were left to rest for 15 min after setting the gap and the temperature. Every measurement for each grease was repeated three times at each temperature. These temperature parameters were selected from our investigation point of view and were determined to monitor the temperature-influenced flow behavior of the biogenic model greases.

\section{Results and Discussion}

\subsection{Frictional Behavior}

Averaged coefficients of friction of all the examined model greases from Fuchs and Pro2TecS obtained in the nanotribometer set-up by applying two different relative speeds are shown in Figure 2. The average standard deviation is described by the error bars in the diagram. Model greases 7, 8, and 9 could not be tested on the nanotribometer due to their coarse structure. In the experiments with these model greases, the rotational movement causes the coarse particles in the grease to contact the ball socket in the cantilever. Consequently, the fiber-optic sensors deflect, even though there was actually 
no friction load. This results in high initial values of the friction coefficient or suddenly high values of friction coefficient during the test.

As can be seen in Figure 2, the reference greases, R1, based on synthetic Ester and Li/Ca-Soap, and $\mathrm{R} 2$, based on Li-12-Hydroxystearate and HOSO, generally show higher frictional values than biogenic grease samples in the present steel ball on steel plate frictional contact situation.

The use of biogrease S2, based on castor oil and lignin/PEGDGE as a thickener, provides similar or lower values of the friction coefficient than the two reference lubricating greases, R1 and R2. Moreover, the biogenic grease sample S4, containing lignin/HMDI as a thickener agent, stands out because of its lowest friction coefficient in comparison with the reference greases R1 and R2 and the other model greases from Pro2TecS: S1, S2, and S3. Another interesting point is that the biogenic grease samples produced by Pro2TecS by applying a relative speed of $40 \mathrm{~mm} \cdot \mathrm{s}^{-1}$ exhibit higher frictional values than the other model greases from Fuchs.

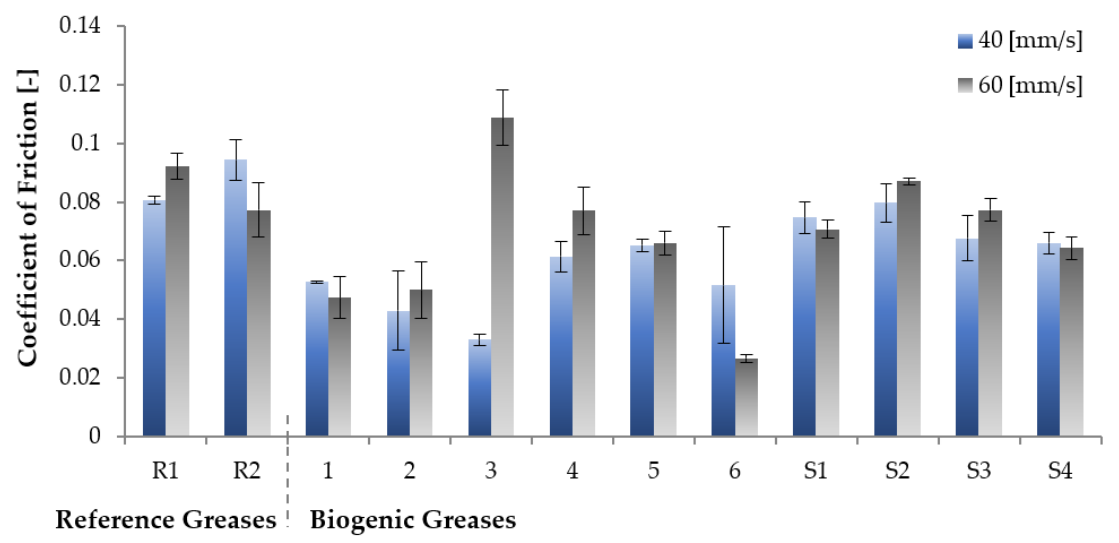

Figure 2. Friction coefficients determined in a steel ball-on-steel disc configuration (wear path $\left.s_{\mathrm{R}}=80 \mathrm{~m}\right)$.

As can be seen in Figure 2, the model biogenic grease 3, based on HOSO, Glycerin, and cellulose ether, has the lowest frictional coefficient at a relative speed of $40 \mathrm{~mm} \cdot \mathrm{s}^{-1}$; nevertheless, this model grease provides the highest frictional value at a relative speed of $60 \mathrm{~mm} \cdot \mathrm{s}^{-1}$ than all of the other examined model greases. In addition, this grease exhibits an adhesive behavior, which could lead to a negative influence on the friction behavior at the nanotribometer. This directly shows the influences of the model grease components on frictional behavior.

Moreover, model greases 1 and 2, based on a mixture of castor oil and HOSO as base oil, as well as model grease 6 , provide lower values of the friction coefficient than the reference greases and the other model biogenic greases. These model greases 1 and 2 also contain glyceryl monostearate and/or sorbitan monostearate, such as biodegradable thickener agents. This optimum frictional behavior can be attributed to both the presence of castor oil with much higher viscosity than HOSO, and the much lower molecular weight of sorbitan and glyceryl monostearates in comparison with the rest of bio-thickeners, that is, biopolymers. In addition, this type of grease exhibits very poor mechanical stability, though this could provide an advantage from a tribological point of view. This means that the microstructure of the grease is easily destroyed inside the tribological contact, turning into a more fluid material, significantly decreasing the consistency, and being able to lubricate contact more effectively [9].

Looking at the detail, the friction coefficients of the greases 1, 5, S1, and S4, remain stable in almost all test series. It shows that the friction coefficients of these grease samples are not highly influenced by relative speed differences.

According to the data in Figure 2, the friction coefficients of some examined greases, especially $\mathrm{R} 1,2,3,4$, S2, and S3, increase with increasing relative speed. This is not the expected relative speed 
influence on the frictional behavior, because the friction coefficient decreases with increasing relative speed in the mixed-friction lubrication regime. This frictional behavior could be explained by taking into account the beginning of the transition to the hydrodynamic lubrication regime. This approach is supported by wear data shown in Figure 4 and discussed below, in which the wear volume obtained in the contact lubricated with R1, 2, 4, S2, and S3 decreases with increasing relative speed.

\subsection{Wear Results}

In this series of experiments, the wear marks on the steel discs, obtained after performing the frictional tests with the normal load of $200 \mathrm{mN}$ and a relative speed of $40 \mathrm{~mm} \cdot \mathrm{s}^{-1}$ in the nanotribometer, were investigated using the white light interferometry (the optical 3D surface profilometer) as displayed in Figure 3. These pictures provide a perspective view of the main contacting area on the steel plate. The wear scars on the steel surface appear quite clearly in the perspective view. As can be seen in Figure 3, while the reference grease R2 and the biogenic greases 3, 4, and 6 produced very wide and strong abrasive wear on the steel plate, the reference grease R1 and the biogenic grease 1 caused the narrowest wear tracks but pronounced abrasive wear. Moreover, the biogenic greases S1, S2, and S3 show wide but less pronounced wear scars on the steel plate. These wear results can be explained by the different components in grease formulations and resulting rheological behaviors.
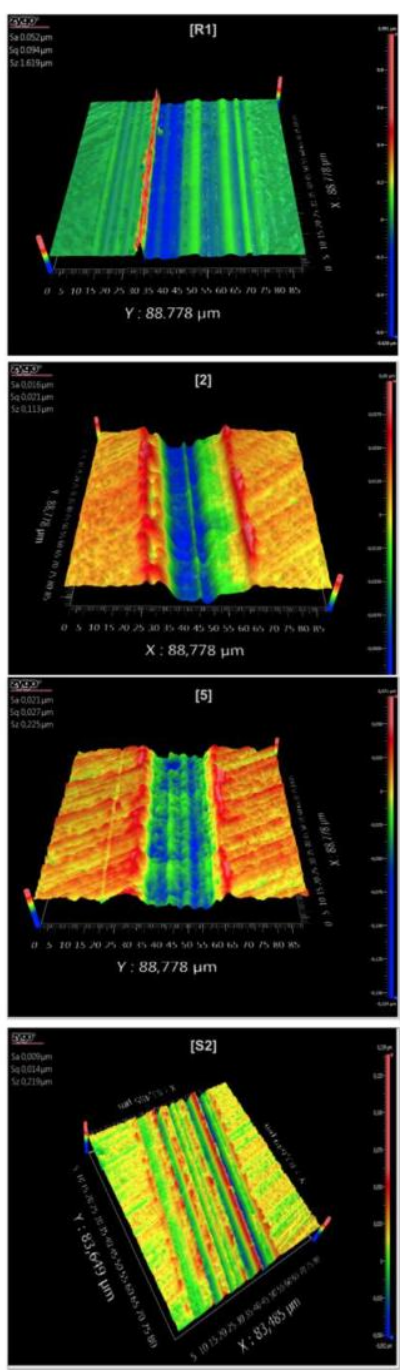
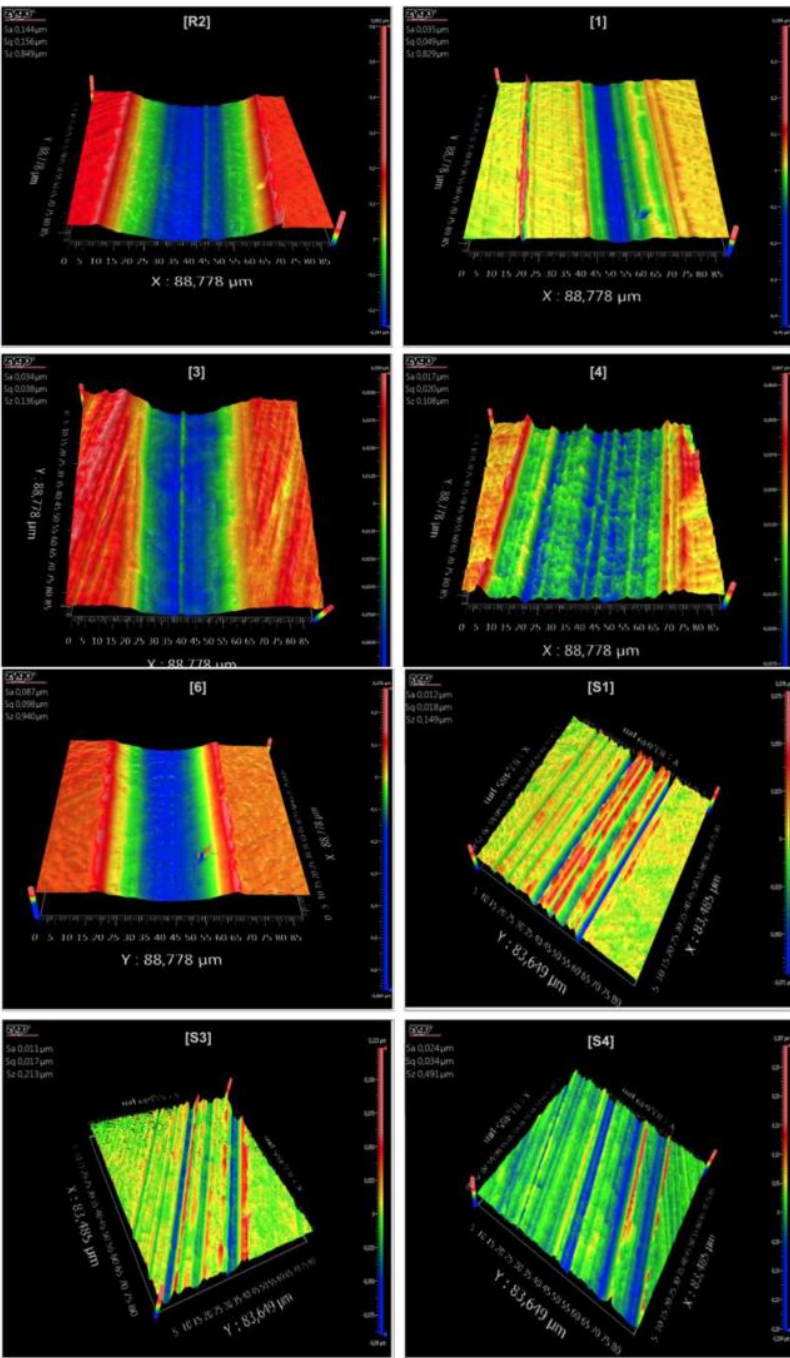

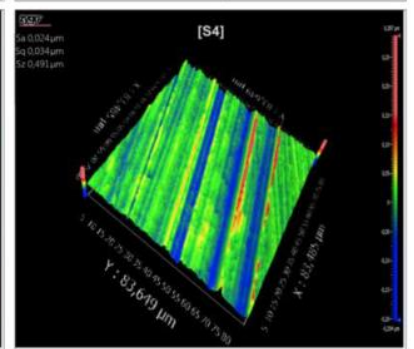

Figure 3. Profilometric pictures obtained from the steel discs as a function of the grease used as lubricants (window sizes of $88,778 \mu \mathrm{m} \times 88,778 \mu \mathrm{m}$ and $83,485 \mu \mathrm{m} \times 83,649 \mu \mathrm{m}$ ). 
The average volumes of the wear tracks on the steel plate, which were obtained after performing the frictional tests in the nanotribometer, are displayed as a function of the two different imposed relative speeds in Figure 4. The average standard deviation is described by the error bars in the diagram.

As can be observed in Figure 2, the friction coefficients of the reference greases are only slightly higher than those of the biogenic greases, despite the significantly higher wear volume values, which were at least three times the wear marks obtained with the biogenic greases.

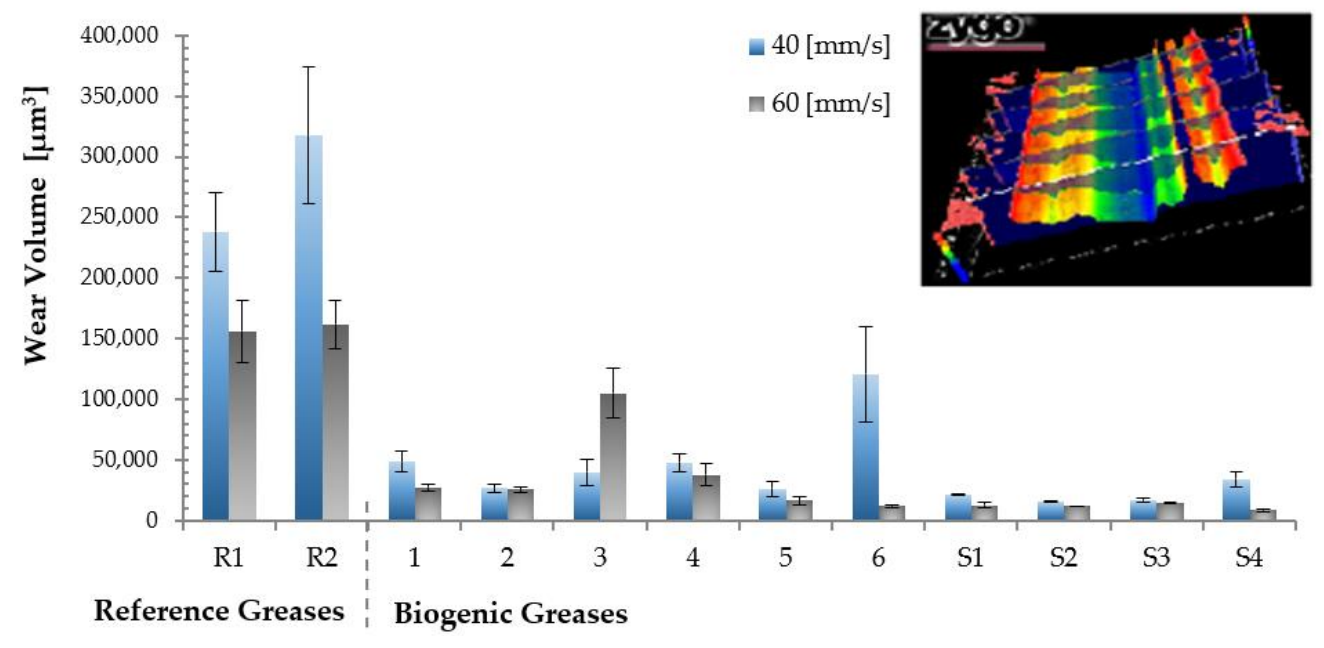

Figure 4. Wear volume in steel disc (Wear path $s_{R}=80 \mathrm{~m}$ ).

Moreover, although biogenic grease 6, prepared with natural cellulose fiber of length of $18 \mu \mathrm{m}$, exhibits the lowest frictional value, it produces the highest wear volume at the lower relative speed of $40 \mathrm{~mm} \cdot \mathrm{s}^{-1}$ compared with all of the other biogenic greases, but the least wear at a relative speed of $60 \mathrm{~mm} \cdot \mathrm{s}^{-1}$.

Another interesting point is that biogenic grease 3 produces a higher value of the friction coefficient at a relative speed of $60 \mathrm{~mm} \cdot \mathrm{s}^{-1}$, which is reflected in the wear volumes. In addition to this, wear volume obtained in the contact lubricated with biogenic grease 3 increases by increasing relative speed, and decreases when using the other biogenic greases.

The biogenic grease samples containing castor oil and lignin/PEDGE or lignin/HMDI-thickener present higher values of the friction coefficient than the other biogenic greases, but the least wear on the steel plates. Under an assumption, these results could be explained by the better mechanical stability of these biogenic greases. This means that grease microstructures achieved by chemically cross-linking castor oil and lignin are not easily broken inside the tribological contact. This property of the grease microstructures could favor the grease not being easily ejected from the contact and therefore increases the efficiency of the grease in the lubricating contact.

\subsection{Rotational Transient Flow Tests}

Figure 5 shows different transient flow curves for selected biogenic and reference grease samples at $25^{\circ} \mathrm{C}$. The rheological energy densities were determined by integration of shear stress over time at $25^{\circ} \mathrm{C}, 40^{\circ} \mathrm{C}$, and $80^{\circ} \mathrm{C}$, according to Equations (1) and (2).

The values of $e_{\text {rheo }}$ for the investigated biogenic greases are displayed in Figure 6. Model greases 1 and 2 could not be tested at $80^{\circ} \mathrm{C}$ on the rheometer, because sorbitan and glyceryl monostearates melted below this temperature [7]. 


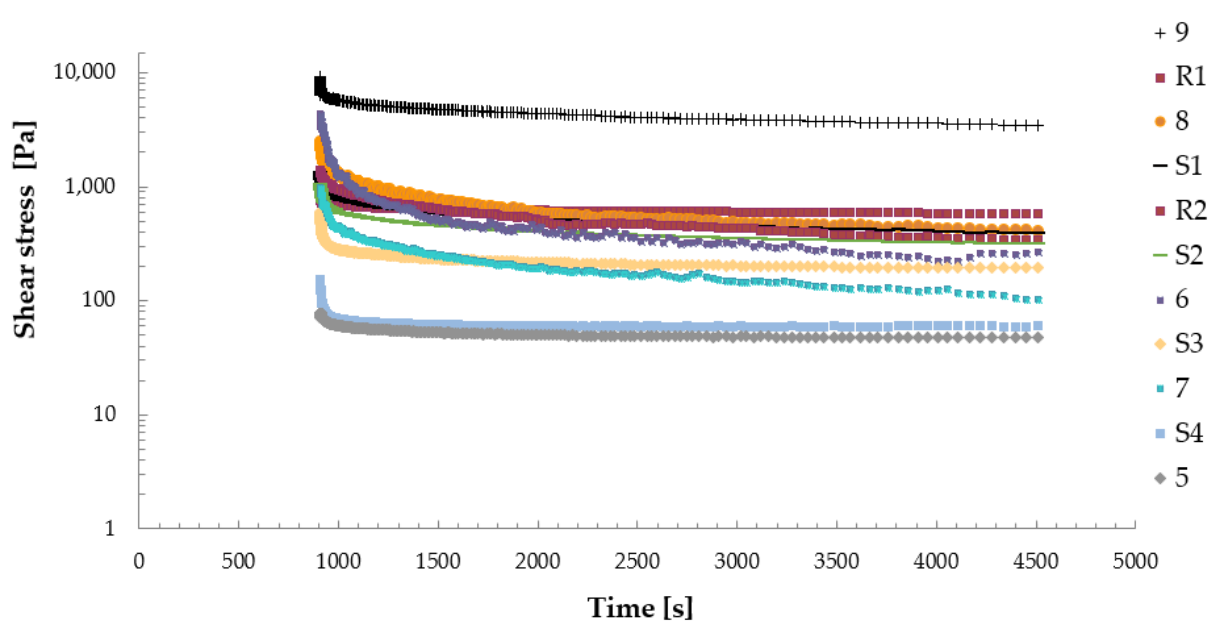

Figure 5. Transient flow curves for selected model grease samples at $25^{\circ} \mathrm{C}$.

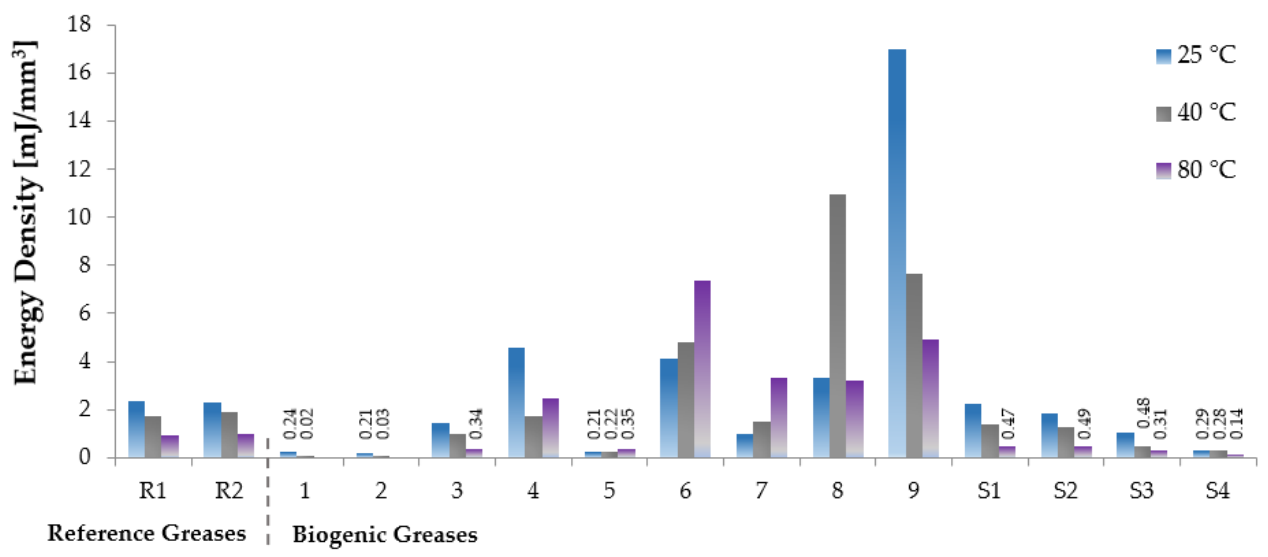

Figure 6. Energy densities $\left(e_{\text {rheo }}\right)$ determined by integration of the shear stress vs. time plots at $25^{\circ} \mathrm{C}$, $40^{\circ} \mathrm{C}$, and $80^{\circ} \mathrm{C}$.

These results show that the energy expenditure depends strongly on the temperature applied during the shearing of model greases at a constant shear rate. As can be seen in Figure 6, high test temperatures generally lead to less energy expenditure than is needed to stress the thickener structure. This indicates that shear-induced structural modifications of the model greases are significantly influenced by the temperature. Unexpectedly, however, the energy density values of the grease samples 5, 6, 7, and 8 (excluding the energy density value of sample 8 at $80^{\circ} \mathrm{C}$ ) increase with increasing temperature. The unusual temperature-influenced flow behavior of these biogenic greases can be explained by the weak interactions between the base oil and cellulosic thickeners, based on hydrogen bonding, which significantly decrease with temperature. This favors oil separation (oil bleeding) at high temperatures, thus increasing viscosity as a result of the higher effective thickener concentration.

Another interesting point is that the biogenic grease samples 6, 8, and 9, consisting of HOSO as a base oil and natural cellulose fiber of length of $18 \mu \mathrm{m}$ and $20-40 \mu \mathrm{m}$ and natural wood pulp from softwood 70-150 $\mu \mathrm{m}$ as thickener agents, exhibit the highest values of energy density in all test series, probably because these formulations need higher thickener concentrations to be physically stabilized. Moreover, model grease samples 1 and 2, based on a mixture of castor oil and HOSO as base oil, and model grease sample 5, stand out because of their low values of the energy density in comparison with the reference greases and the other model biogenic greases. Looking at the detail, biogenic greases S3 and S4, based on lignin/HMDI as a thickener, provide less energy expenditure compared with 
biogenic grease samples S1 and S2, based on lignin/PEGDGE as a thickener. This shows that the energy expenditure due to the shearing process is also influenced by the kind of lignin chemical modification.

From the analysis of the results discussed above, it seems obvious that grease microstructure plays an important role in the friction process. For a better understanding of the influence of the grease structure on the tribological behavior, it is necessary to investigate the relationship between the rheological energy density and grease structure. Therefore, the microstructure of some biogenic greases was examined by means of transmitted light microscopy.

The microstructures of selected biogenic greases are shown in Figure 7. As can be observed, the geometry and the distribution of the thickener particles are clearly different. The biogenic grease samples 1, 3, and 5 display rather homogeneous structures. This is especially relevant in samples 3 and 5, where the thickener and base oil cannot be clearly distinguished from each other. By contrast, the thickeners in the biogenic grease samples 6, 8, 9, S1, S2, and S3 are conspicuous. At first consideration, from the thickener structures and the rheological energy density point of view, one detects that the homogeneous structure of grease sample 5 provides the lowest values of energy density at $25{ }^{\circ} \mathrm{C}$ and $40{ }^{\circ} \mathrm{C}$ (see Figure 6), compared with samples 6, 8, 9, S1, S2, and S3, which show thickener agglomerates in the form of platelets or granules. On the other hand, the model grease sample 1 , based on glyceryl monostearate as thickener agent, exhibits less energy expenditure than model grease sample 3, based on cellulose ether as thickener agent, which provides higher values of the rheological energy density (see Figure 6). Overall, these results reflect the fact that the characteristics and type of the thickener microstructure influence the friction behavior of the grease in the tribological process. In general, the more homogenous the structure and the smaller the particle size, the lower the resulting energy density.
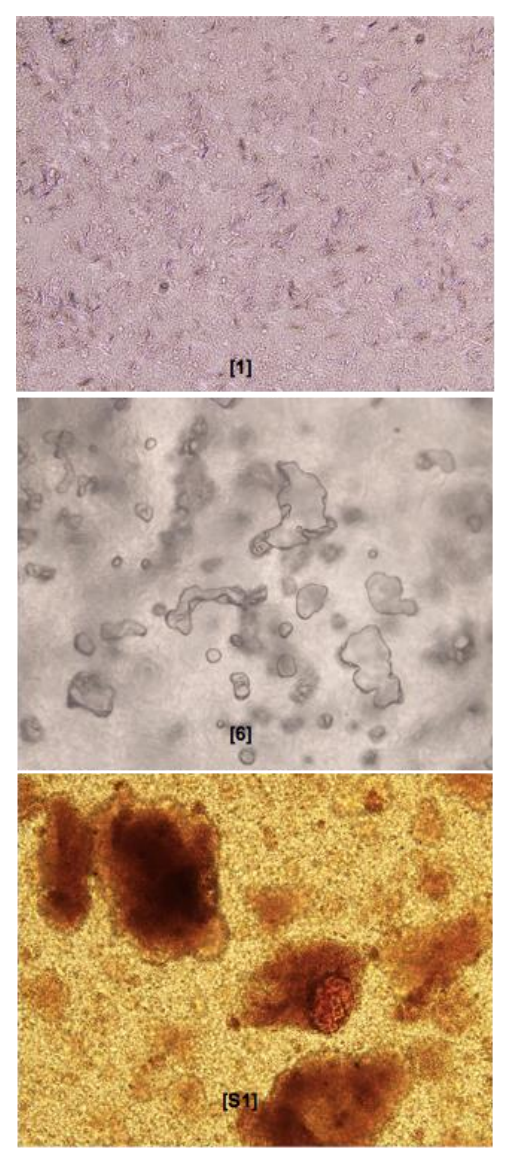
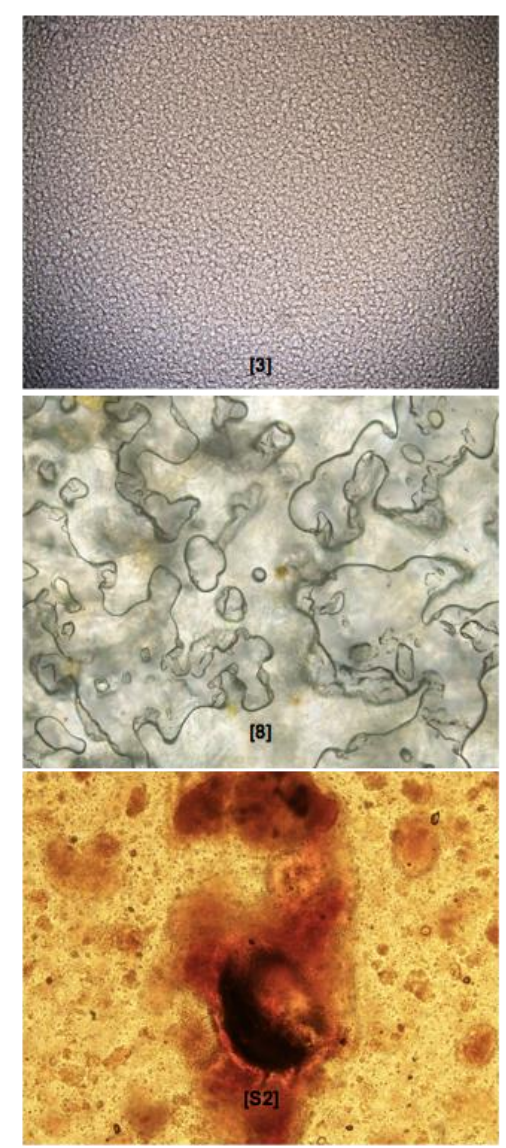
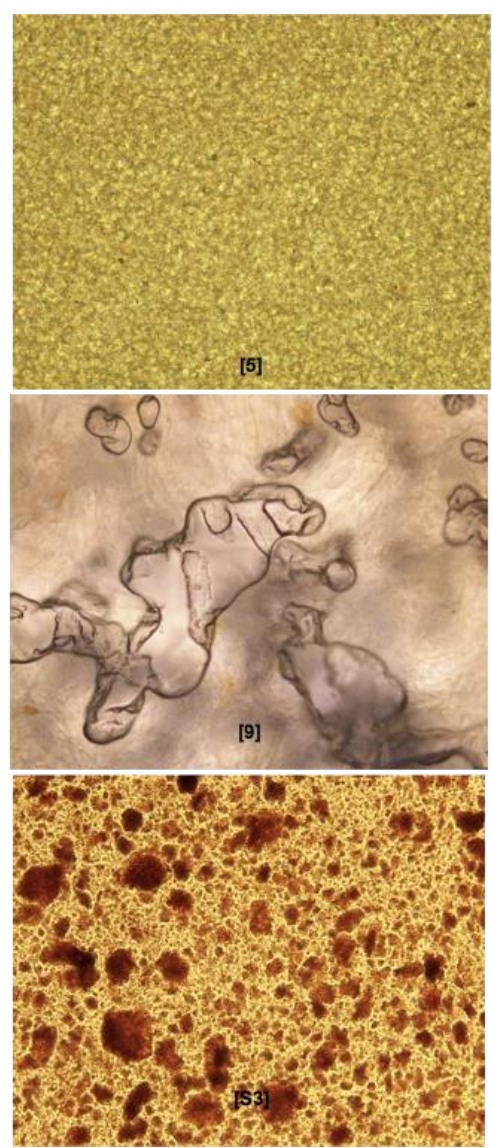

Figure 7. Transmitted Light Microscope micrographs for examined biogenic grease samples (window sizes of $683.5 \mu \mathrm{m} \times 536 \mu \mathrm{m}$ ) [19]. 


\section{Conclusions}

Several bio-sourced materials were used as thickener agents to formulate complete biogenic lubricating greases. These samples were tribologically investigated in a nanotribometer and in a rheometer, and compared with traditional lithium-12-hydroxystearate/HOSO and lithium-calcium soap/synthetic ester greases. Results from the nanotribometer tests showed a different influence of completely biogenic model grease components on frictional and wear behavior. In almost all cases, the use of biodegradable model greases produced lower values of the friction coefficient than the reference greases. The model greases containing glyceryl- and sorbitan monostearate as thickener agents, and the combination of HOSO and castor oil as base oil, generally yielded the lowest values of the friction coefficient no matter the test conditions. The reference greases produced higher values of the wear volume on the steel plate despite exhibiting only slightly higher friction coefficient values than the model greases. Moreover, the use of biogenic greases based on only castor oil as the base oil exhibited the lowest wear volume on the steel plate; however, these biogenic greases provided higher frictional coefficients (especially at relative speed of $40 \mathrm{~mm} \cdot \mathrm{s}^{-1}$ ), compared with biogenic greases consisting of HOSO or a combination of HOSO and castor oil.

To investigate the fluid friction behavior of the biodegradable model greases and to quantify the rheological energy by shearing the grease, transient flow tests were performed at different temperatures. The estimation of the energy density from the shear stress versus time curve revealed that the amount of energy expenditure per stressed volume $\left(e_{\text {rheo }}\right)$ strongly depends on the test temperature. In this sense, the rheological energy density $\left(e_{\text {rheo }}\right)$ generally decreased by increasing the test temperature. However, the opposite tendency was found for some model biogenic greases. These results can be explained by the thickener microstructure and the thickener/base oil interactions. Weak physical interactions like those expected between the base oil and cellulosic thickeners may also favor oil separation (oil bleeding) at high temperatures, resulting in higher viscosity and therefore higher energy density. The biogenic grease samples consisting of a combination of HOSO and castor oil as the base oil and glyceryl- and/or sorbitan monostearate as thickener yielded the lowest energy expenditure at $25^{\circ} \mathrm{C}$ and $40^{\circ} \mathrm{C}$. Moreover, biogenic model greases based on lignosulfonate or chemically-modified lignin as thickener agents provided less energy expenditure than biogenic model greases based on Isoprene derivatives, natural cellulose fibers, or natural wood pulp from softwood, the latter also provided higher values of the energy expenditure by friction process compared with the reference greases.

In this paper, the fluid friction can be defined as the energy expenditure during the relative motion of the shearing process. In this sense, correspondence between the rheological energy density $\left(e_{\text {rheo }}\right)$ and the friction coefficient can be inferred for some model greases. Biogenic greases with less energy expenditure during the flow process, such as grease samples 1,2, and S4 showed low values of the friction coefficient. In addition to this, semi-biogenic greases (reference greases), which showed the highest values of the friction coefficient, exhibited high energy density values compared with most of the biogenic greases studied.

Author Contributions: The paper was created by Nazli Acar. Erik Kuhn und José M. Franco contributed by supervising the experimental works and amending text passages.

Funding: This research was funded by German Ministry of Education and Research grant number FKZ13FH018IX4.

Acknowledgments: This work, which is part of the research Project "Tribiogen", was supported by German Ministry of Education and Research. The authors gratefully acknowledge the financial support. Authors also acknowledge Fuchs Europe Schmierstoffe (Germany), Fuchs Lubritech (Germany), and Pro2TecS (University of Huelva (Spain)) for kindly providing model samples.

Conflicts of Interest: The authors declare no conflict of interest.

\section{References}

1. Sukirno, R.F.; Setijo, B.; Mohammad, N. Biogrease based on palm oil and lithium soap thickener: Evaluation of antiwear property. World Appl. Sci. J. 2009, 6, 401-407. 
2. Fajar, R. Nasikin. Anti-wear properties of bio-grease from modified palm oil and calcium soap thickener. CIGR J. 2010, 12, 64-69.

3. Abdulbari, H.A.; Rosli, M.Y.; Abdurrahman, H.N.; Nizam, M.K. Lubricating grease from spent bleaching earth and waste cooking oil: Tribology properties. Inter. J. Phys. Sci. 2011, 6, 4695-4699.

4. El-Adly, R.A.; Ahmed, H.B.; Modather, F.H. Jojoba and Castor Oils as Fluids for the preparation of bio greases: A Comparative Study. Inter. J. Sci. Eng. Res. 2014, 5, 2229-5518.

5. Panchal, T.; Chauhan, D.; Thomas, M.; Patel, J. Bio based grease a value added product from renewable resources. Ind. Crop. Prod. 2015, 63, 48-52. [CrossRef]

6. Nagendramma, P.; Kumar, P. Eco-Friendly Multipurpose Lubricating Greases from Vegetable Residual Oils. Lubricants 2015, 3, 628-636. [CrossRef]

7. Sánchez, R.; Franco, J.M.; Delgado, M.A.; Valencia, C.; Gallegos, C. Effect of thermo-mechanical processing on the rheology of oleogels potentially applicable as biodegradable lubricating greases. Chem. Eng. Res. Des. 2008, 86, 1073-1082. [CrossRef]

8. Sánchez, R.; Franco, J.M.; Delgado, M.A.; Valencia, C.; Gallegos, C. Development of new green lubricating greases formulations based on cellulosic derivatives and castor oil. Green. Chem. 2009, 11, 686-693. [CrossRef]

9. Sánchez, R.; Franco, J.M.; Kuhn, E.; Fiedler, M. Tribological characterization of green lubricating greases formulated with castor oil and different biogenic thickener agents: a comparative experimental study. Ind. Lubr. Tribol. 2011, 63, 446-452. [CrossRef]

10. Sánchez, R.; Franco, J.M.; Delgado, M.A.; Valencia, C.; Gallegos, C. Thermal and mechanical characterization of cellulosic derivatives-based oleogels potentially applicable as bio-lubricating greases: Influence of ethyl cellulose molecular weight. Carbohydr. Polym. 2011, 83, 151-158. [CrossRef]

11. Sánchez, R.; Stringari, G.B.; Franco, J.M.; Valencia, C.; Gallegos, C. Use of chitin, chitosan and acylated derivatives as thickener agents of vegetable oils for bio lubricant applications. Carbohydr. Polym. 2011, 85, 705-714. [CrossRef]

12. Alfonso, J.E.M.; Yañez, R.; Valencia, C.; Franco, J.M.; Díaz, M.J. Optimization of the Methylation Conditions of Kraft Cellulose Pulp for Its Use As a Thickener Agent in Biodegradable Lubricating Greases. Ind. Eng. Chem. Res. 2009, 48, 6765-6771. [CrossRef]

13. Núñez, N.; Alfonso, J.E.M.; Valencia, C.; Sánchez, M.C.; Franco, J.M. Rheology of new green lubricating grease formulations containing cellulose pulp and its methylated derivative as thickener agents. Ind. Crop. Prod. 2012, 37, 500-507. [CrossRef]

14. Borrero-López, A.M.; Valencia, C.; Franco, J.M. Rheology of lignin-based chemical oleogels prepared using diisocyanate crosslinkers: Effect of the diisocyanate and curing kinetics. Europ. Polym. J. 2017, 89, 311-323. [CrossRef]

15. Triviño, E.C.; Valencia, C.; Franco, J.M. Influence of epoxidation conditions on the rheological properties of gel-like dispersions of epoxidized kraft lignin in castor oil. Holzforschung 2017, 71, 777-784.

16. Kuhn, E. Zur Tribologie der Schmierfette: Eine energetische Betrachtungsweise des Reibungs- und Verschleißprozesses; Expert Verlag: Renningen, Germany, 2017.

17. Delgado, M.A.; Franco, J.M.; Kuhn, E. Effect of rheological behaviour of lithium greases on the friction process. Ind. Lubr. Tribol. 2008, 60, 37-45. [CrossRef]

18. Kuhn, E. Experimental grease investigations from an energy point of view. Ind. Lubr. Tribol. 1999, 51, $246-251$. [CrossRef]

19. Slabka, I. Rheologische Charakterisierung Biogener Modellfette. Master's Thesis, Hamburg University of Applied Sciences, Hamburg, Germany, 2017.

20. Kuhn, E. An algorithm to estimate the friction energy of a grease lubricated contact. Ind. Lubr. Tribol. 2000, 52, 174-177. [CrossRef]

21. Delgado, M.A.; Franco, J.M.; Valencia, C.; Kuhn, E.; Gallegos, C. Transient shear flow of model lithium lubricating greases. Mech. Time-Depend. Mater. 2009, 13, 63-80. [CrossRef]

22. Mohr, H. Tribologische Untersuchungen Komplett Biogener Schmierfette. Master's Thesis, Hamburg University of Applied Sciences, Hamburg, Germany, 2017.

(C) 2018 by the authors. Licensee MDPI, Basel, Switzerland. This article is an open access article distributed under the terms and conditions of the Creative Commons Attribution (CC BY) license (http:/ / creativecommons.org/licenses/by/4.0/). 